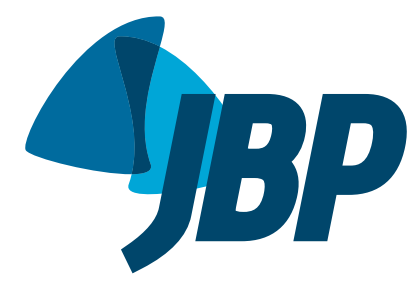

1. Divisão de Pneumologia, Instituto do Coração - InCor - Hospital das Clínicas, Faculdade de Medicina, Universidade de São Paulo, São Paulo (SP) Brasil.

2. Coordenação de RM e TC Cardiovascular, Instituto do Coração InCor - Hospital das Clínicas, Faculdade de Medicina, Universidade de São Paulo, São Paulo (SP) Brasil.

a. (D) http://orcid.org/0000-0002-3057-5716

b. (iD http://orcid.org/0000-0002-6344-2127

c. (D) http://orcid.org/0000-0002-5132-1934

d. (D) http://orcid.org/0000-0001-5121-0129

e. (iD http://orcid.org/0000-0003-4505-3344

f. (D) http://orcid.org/0000-0002-1851-2667

g. (iD http://orcid.org/0000-0001-5572-4397

h. (D) http://orcid.org/0000-0002-7217-9498

Submitted: 10 August 2017. Accepted: 17 December 2017.

Study carried out in the Divisão de Pneumologia, Instituto do Coração - InCor - Hospital das Clínicas, Faculdade de Medicina, Universidade de São Paulo, São Paulo (SP) Brasil.

\section{Spirometry in patients screened for coronary artery disease: is it useful?}

\author{
Frederico Leon Arrabal Fernandes',a, Regina Maria Carvalho-Pinto1,b, \\ Rafael Stelmach ${ }^{1, c}$, João Marcos Salge ${ }^{1, d}$, Carlos Eduardo Rochitte ${ }^{2, e}$, \\ Eliane Cardoso dos Santos Souza ${ }^{1, \mathrm{f}}$, Janaina Danielle Pessi ${ }^{1, \mathrm{~g}}$, Alberto Cukier ${ }^{1, \mathrm{~h}}$
}

\begin{abstract}
Objective: To determine the prevalence of spirometric abnormalities in patients screened for coronary artery disease (CAD) and the risk factors for lung function impairment. Methods: Patients referred for cardiac CT underwent spirometry and were subsequently divided into two groups, namely normal lung function and abnormal lung function. The prevalence of spirometric abnormalities was calculated for the following subgroups of patients: smokers, patients with metabolic syndrome, elderly patients, and patients with obstructive coronary lesions. All groups and subgroups were compared in terms of the coronary artery calcium score and the Duke CAD severity index. Results: A total of 205 patients completed the study. Of those, $147(72 \%)$ had normal lung function and 58 (28\%) had abnormal lung function. The median coronary artery calcium score was 1 for the patients with normal lung function and 36 for those with abnormal lung function $(p=0.01)$. The mean Duke CAD severity index was 15 for the former and 27 for the latter $(p<0.01)$. Being a smoker was associated with the highest OR for abnormal lung function, followed by being over 65 years of age and having obstructive coronary lesions. Conclusions: The prevalence of spirometric abnormalities appears to be high in patients undergoing cardiac CT for CAD screening. Smokers, elderly individuals, and patients with $\mathrm{CAD}$ are at an increased risk of lung function abnormalities and therefore should undergo spirometry.
\end{abstract}

(ClinicalTrials.gov identifier: NCT01734629 [http://www.clinicaltrials.gov/])

Keywords: Pulmonary disease, chronic obstructive; Spirometry; Coronary disease; Tomography, X-ray computed.

\section{INTRODUCTION}

Pulmonary function tests constitute an important tool for evaluating lung disease and dyspnea. Chronic respiratory diseases remain underdiagnosed. In a study conducted in Canada, only $32 \%$ of patients with COPD had previously been diagnosed with the disease. In a large epidemiological study conducted in the United States, $15 \%$ of adults over 45 years of age were found to have undiagnosed airflow obstruction. ${ }^{(1-3)}$

In clinical practice, patients suspected of having coronary artery disease (CAD) commonly undergo extensive and expensive testing. Although coexistence of CAD and respiratory disease is common, pulmonary function tests are not commonly performed in heart disease patients. Spirometry is performed in less than $30 \%$ of patients examined for dyspnea by a cardiologist. ${ }^{(4)}$

The use of spirometry in primary care doubles the diagnosis of respiratory disorders, spirometry being safe and accurate for early diagnosis. ${ }^{(5,6)}$ Although spirometry is simple, inexpensive, and highly accurate for detecting lung disease, the possibility of false positives has led a US task force to recommend against the use of spirometry to screen adults for COPD. ${ }^{(7)}$ However, there is recent evidence that the use of spirometry to screen high-risk patients reduces false positives; in addition, new treatment options for patients with COPD have been shown to be effective in changing the natural history of the disease, reinforcing the importance of early diagnosis. ${ }^{(8-10)}$

Spirometry can aid in assessing cardiovascular risk. A reduction in percent predicted $\mathrm{FEV}_{1}$ is a risk factor for cardiovascular mortality independent of traditional risk factors, such as hypertension, dyslipidemia, and smoking. Population-based studies and a systematic review including over 80,000 patients showed that reduced $\mathrm{FEV}_{1}$ is a predictor of mortality. ${ }^{(11-14)}$

Patients with risk factors for cardiovascular disease, such as smoking and a sedentary lifestyle, are at an increased risk of lung disease and might benefit from spirometry. Many such patients undergo cardiac CT for the detection of CAD.

Cardiac CT is an accurate method for diagnosing CAD. In addition to providing anatomic evaluation, cardiac CT has prognostic implications even in asymptomatic individuals, assisting in predicting cardiovascular events. The coronary artery calcium (CAC) score objectively quantifies CAC and constitutes a method for estimating the risk of cardiovascular events. ${ }^{(15,16)}$

Correspondence to:

Frederico Fernandes. Avenida Dr. Enéas de Carvalho Aguiar, 44, Cerqueira Cesar, CEP 05403-000, São Paulo, SP, Brasil.

Tel.: 5511 2661-5034. E-mail: fredlaf@gmail.com

Financial support: This study received financial support from the Fundação de Amparo à Pesquisa do Estado de São Paulo (FAPESP, São Paulo Research

Foundation). 
Given the frequent association between COPD and $C A D,{ }^{(14)}$ the increased cardiovascular mortality risk associated with reduced $\mathrm{FEV}_{1}$, and the fact that pulmonary disease is underdiagnosed, it is likely that many patients undergoing CAD workup have reduced lung function.

Despite being commonly encountered in clinical practice, patients suspected of having CAD but without an established diagnosis of the disease have been the focus of few epidemiological studies. Therefore, the objective of the present study was to determine the prevalence of impaired lung function in this population. A secondary objective was to determine patient characteristics commonly associated with spirometric abnormalities, in order to define a group of patients who might benefit the most from spirometry.

\section{METHODS}

This was a cross-sectional study conducted at a tertiary cardiac hospital. Patients over 40 years of age referred for cardiac CT were screened. Those with previously diagnosed CAD, prior myocardial infarction, a history of revascularization, class III or IV angina pectoris, ${ }^{(17)}$ cognitive impairment precluding spirometry, or decompensated heart failure were excluded. ${ }^{(18)}$ The study protocol was approved by the University of São Paulo School of Medicine Hospital das Clínicas Research Ethics Committee (Protocol no. 0503/11), located in the city of São Paulo, Brazil, and all participants gave written informed consent.

All screened patients completed a questionnaire assessing demographics, symptoms, smoking status, comorbidities, history of pulmonary disease, and medication use. Dyspnea was quantified by the modified Medical Research Council scale. ${ }^{(19)}$ Waist circumference, hip circumference, and waist-to-hip ratio were measured. Metabolic syndrome was determined on the basis of established criteria. ${ }^{(20)}$

Cardiac CT was performed with a 64-row CT scanner (Aquilion 64; Toshiba Medical Systems Corporation, Otawara, Japan). The images were analyzed by institutional radiologists blinded to the spirometry results. CAC was quantified by a radiologist using the Agatston method. The Duke CAD severity index was then calculated on the basis of the degree and location of stenosis. Although the Duke CAD severity index was originally developed for coronary angiography, it has been shown to correlate well with coronary CT angiography. ${ }^{(21,22)}$

All spirometric tests were performed with a $\mathrm{KoKo}^{\circledR}$ PFT spirometer (nSpire Health, Inc., Longmont, CO, USA). Spirometry was performed in accordance with the American Thoracic Society/European Respiratory Society criteria. ${ }^{(23)}$ All spirometric variables were expressed as absolute values and as a percentage of the predicted values for the Brazilian population. (24) Participants were divided into two groups on the basis of post-bronchodilator spirometry results: normal lung function, comprising patients with post-bronchodilator
FVC, FEV , and FEV $_{1} /$ FVC above the lower limit of normal; and abnormal lung function, comprising patients with post-bronchodilator FVC, $\mathrm{FEV}_{1}$, or $\mathrm{FEV}_{1} / \mathrm{FVC}$ below the lower limit of normal. The patients who presented with abnormal lung function were subdivided into two groups on the basis of their functional impairment: persistent obstructive lung disease, comprising patients with post-bronchodilator $\mathrm{FEV}_{1} / \mathrm{FVC}$ below the lower limit of normal; and preserved ratio impaired spirometry (PRISm), comprising patients with post-bronchodilator FVC below the lower limit of normal and normal FEV I $_{1}$ FVC. ${ }^{(25)}$

The degree of lung function impairment was determined on the basis of the Brazilian Thoracic Association guidelines for pulmonary function testing. ${ }^{(26)}$ Although the Global Initiative for Chronic Obstructive Lung Disease guidelines define airway obstruction as an $\mathrm{FEV}_{1} / \mathrm{FVC}$ ratio of $<0.70$, a decision was made to use an $\mathrm{FEV}_{1} / \mathrm{FVC}$ ratio below the lower limit of normal in the present study in order to avoid overdiagnosis of obstructive lung disease in the elderly. ${ }^{(27)}$

Statistical analysis was performed with PASW Statistics for Windows, version 18.0 (SPSS Inc., Chicago, IL, USA). The probability of a type I error was set at 0.05 .

The prevalence of spirometric abnormalities was calculated by dividing the number of individuals in the abnormal lung function, persistent obstructive lung disease, and PRISm groups by the total study population. The prevalence of spirometric abnormalities was also calculated for the following subgroups of patients: smokers (current and former), patients with metabolic syndrome, elderly patients, and patients with obstructive coronary lesions.

The normal lung function group was compared with the abnormal lung function group in terms of anthropometric characteristics, smoking status, pulmonary disease, pulmonary symptoms, abdominal circumference, hip circumference, waist-to-hip ratio, spirometric variables, the CAC score, and the Duke CAD severity index. Categorical variables were compared by using the chi-square test. Parametric variables were compared by using the Student's t-test. Nonparametric variables were compared by using the Mann-Whitney test.

The normal lung function group was also compared with the persistent obstructive lung disease and PRISm subgroups by using ANOVA. For cases in which there were significant differences between groups, the Bonferroni test or Dunnett's test was used for multiple comparisons in order to determine which groups differed from one another.

To determine the predictors of impaired lung function, the ORs for having abnormal lung function (including persistent obstructive lung disease and PRISm) were calculated for the following subgroups of patients: smokers and nonsmokers; patients with and without metabolic syndrome; obese and nonobese patients; patients under and over 65 years of age; patients with and without hypertension; patients with and without diabetes; and patients with and without obstructive 
coronary lesions. To determine the factors influencing the presence of abnormal lung function, forward stepwise logistic regression analysis was performed, all of the variables showing $p<0.20$ in the comparison between patients with normal lung function and those with abnormal lung function being included in the initial model. To detect a $25 \%$ difference in the prevalence of obstructive coronary lesions between the normal lung function and abnormal lung function groups, with a power of $80 \%$ and a type I error of 0.05 , the required sample size was calculated to be 50 per group.

\section{RESULTS}

Between April of 2011 and December of 2013, 381 patients were invited to participate in the study. Of those, 66 declined to participate, 86 had previously undergone revascularization, 11 were unable to perform spirometry, and 13 were excluded because of a history of myocardial infarction, angina, or decompensated heart failure.

A total of 205 patients completed the study. Of those, 168 underwent coronary CT angiography for symptoms of heart disease, including chest pain and dyspnea. Of the 205 patients who completed the study, 147 (72\%) had normal lung function and $58(28 \%)$ had abnormal lung function. Of those, 23 had persistent obstructive lung disease and 35 had PRISm. Figure 1 shows a flow chart of the sample selection process. The CAC score was calculated for all 205 study participants. A total of 188 patients underwent coronary CT angiography and CAC scoringe.

Of the 35 patients with PRISm, 30 had mild spirometric abnormalities, 2 had moderate spirometric abnormalities, and 3 had severe spirometric abnormalities. Of the 23 patients with persistent obstructive lung disease, 19 had mild spirometric abnormalities, 2 had moderate spirometric abnormalities, and 2 had severe spirometric abnormalities. ${ }^{(26)}$

Figure 2 shows the proportions of patients with normal lung function and abnormal lung function (the latter including those with persistent obstructive lung disease and those with PRISm) in the study sample. There were significant differences between the normal lung function and abnormal lung function groups in terms of the proportions of smokers and nonsmokers, and the proportions of elderly and nonelderly patients ( $p<$ 0.01 ). However, there were no significant differences between the two groups regarding the proportions of patients with and without metabolic syndrome ( $p$ $=0.17$ ).

Of the 188 patients who underwent coronary CT angiography, 142 were found to have no coronary obstruction and 46 were found to have some degree of CAD. There were significant differences between the subgroups of patients with and without coronary obstruction regarding spirometric patterns ( $p=0.04$; Figure 2).

All groups were compared in terms of their major characteristics (Table 1). They were all found to be similar in terms of sex, weight, height, body mass index (BMI), metabolic syndrome, and hip circumference.

Patients with abnormal lung function were found to be older than those with normal lung function ( $p$ $<0.01$ ). In addition, the proportions of smokers and former smokers were higher among the patients with abnormal lung function than among those with normal lung function, as were the proportions of patients with a history of pulmonary disease and increased waist-to-hip ratio ( $p<0.01$ for all). Abdominal circumference was found to be significantly higher in the abnormal lung function group and in the PRISm subgroup than in the normal lung function group ( $p=0.03$ ), although not in the persistent obstructive lung disease subgroup.

Of the sample as a whole, 94 (45.8\%) had a CAC score of zero. In addition, $9.8 \%$ were found to have mild CAC, whereas $44.4 \%$ were found to have moderate or severe CAC. The median CAC score for the normal lung function group was 1 , being significantly lower than those for the abnormal lung function and PRISm groups (36 and 55, respectively; $\mathrm{p}<0.05$; Figure $3)$. This difference remained significant even after adjustment for age, BMI, smoking, and metabolic syndrome $(p=0.04)$.

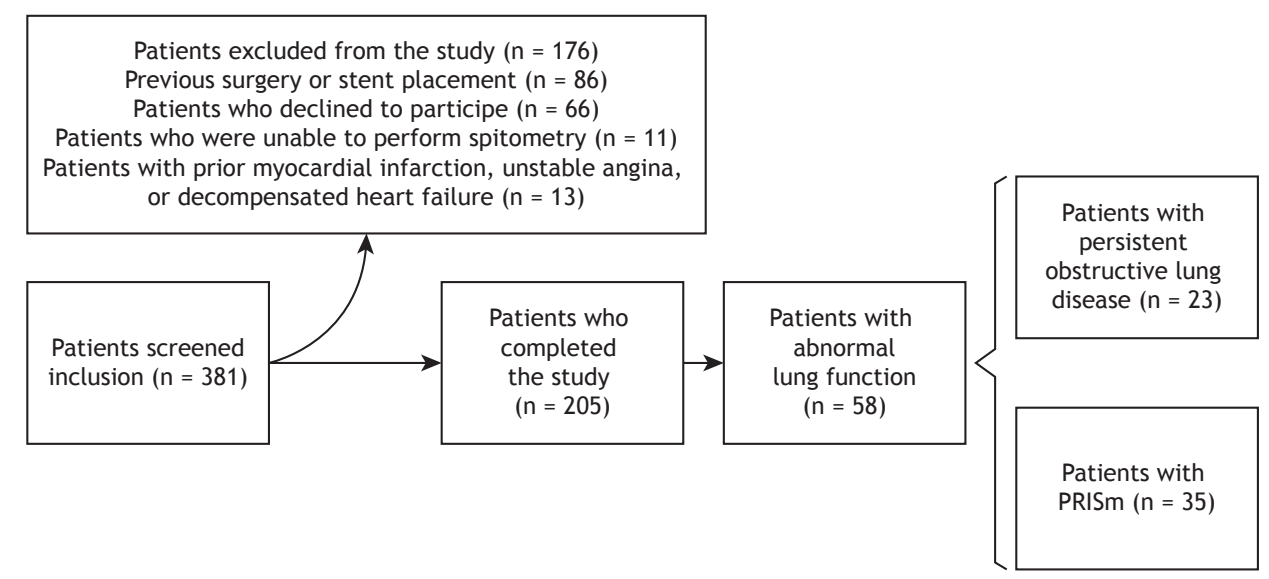

Figure 1. Patient recruitment flow chart. PRISm: preserved ratio impaired spirometry. 


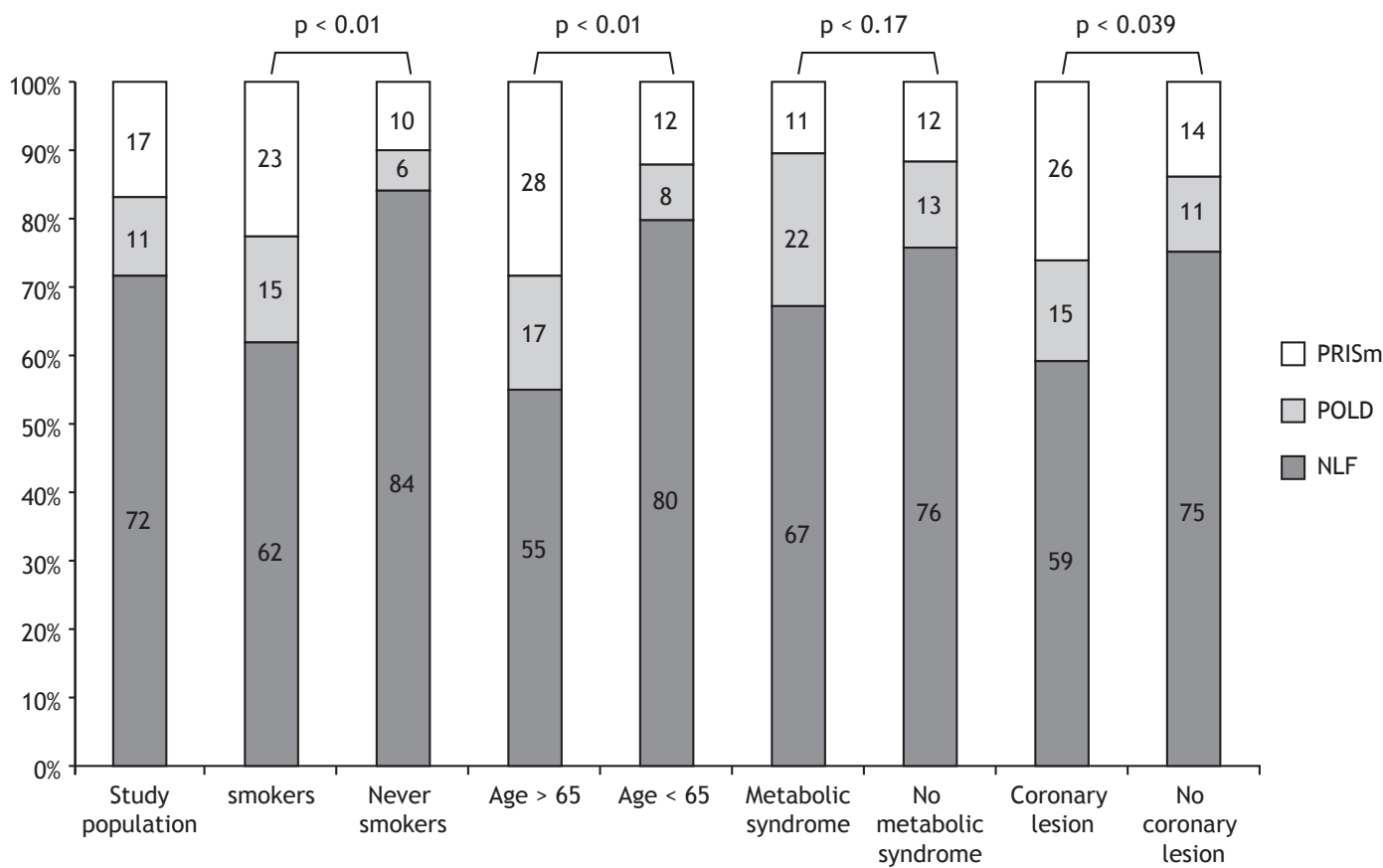

Figure 2. Proportions of patients in each subgroup. Note significant differences between the proportions of smokers and never smokers; elderly and nonelderly patients; and patients with and without coronary lesions. Despite an increased proportion of patients with metabolic syndrome among those with abnormal lung function, the difference in proportions between patients with and without metabolic syndrome was not significant. PRISm: preserved ratio impaired spirometry; POLD: persistent obstructive lung disease; and NLF: normal lung function. Values of $p$ represent the differences in proportions of patients among the subgroups, as assessed by the chi-square test.

The Duke CAD severity index, which reflects the severity of obstruction and the number of diseased vessels, was calculated. ${ }^{(21)}$ Of the sample as a whole, 118 had a Duke CAD severity index of zero. The median Duke CAD severity index for the normal lung function group was 15 , being significantly lower than that for the abnormal lung function group (i.e., 27; $p<0.01$ ).

The prevalence of chronic respiratory disease was found to be higher in the abnormal lung function group than in the normal lung function group ( $p<0.001$ ). In the group of patients with abnormal lung function, 11 had a previous diagnosis of chronic pulmonary disease, and 6 were receiving treatment for it. In the group of patients with normal lung function, 7 had a history of chronic pulmonary disease, and only 1 took medication regularly. No differences were found between the abnormal lung function and normal lung function groups regarding the frequency of symptoms (Figure 4). In addition, no differences were found between the two groups regarding the severity of dyspnea, as assessed by the modified Medical Research Council scale $(p=0.81)$. Dyspnea was not significant as a predictor of abnormal lung function.

In order to determine the variables associated with abnormal lung function, we calculated the ORs for presenting with spirometric abnormalities (Table 2). Being a smoker was associated with the highest OR for abnormal lung function, followed by being over 65 years of age and having obstructive coronary lesions. Logistic regression controlling for sex, age,
BMI, smoking, obstructive coronary lesions, metabolic syndrome, hypertension, and diabetes mellitus showed that smoking and age were factors independently associated with abnormal lung function.

\section{DISCUSSION}

The present study included 205 patients undergoing cardiac CT for CAD screening. None of the participants had previously been diagnosed with cardiovascular disease. Although this patient profile is common in clinical practice, such patients constitute an understudied population. This population was chosen precisely because it is a real-life sample of patients commonly encountered by internists, cardiologists, and pulmonologists. Our finding of abnormal spirometry in $28 \%$ of the study participants demonstrates that lung function abnormalities and respiratory disease are often neglected and underdiagnosed in patients screened for cardiac conditions or symptoms.

The 2011 American Board of Internal Medicine Foundation initiative known as Choosing Wisely was introduced in order to alert physicians to excessive testing in many clinical situations, including CAD. ${ }^{(28)}$ In our study population, most of the patients had negative cardiac CT findings, which are indicative of excessive testing. In contrast, spirometry is underused, even in patients with respiratory symptoms. ${ }^{(29)}$

The prevalence of spirometric abnormalities in the present study was highest in smokers (current and 
Table 1. Demographic, clinical, and functional characteristics of the study sample. ${ }^{a}$

\begin{tabular}{|c|c|c|c|c|}
\hline Characteristic & $\begin{array}{l}\text { Normal lung } \\
\text { function }\end{array}$ & $\begin{array}{l}\text { Abnormal lung } \\
\text { function }\end{array}$ & $\begin{array}{c}\text { Preserved ratio } \\
\text { impaired spirometry }\end{array}$ & $\begin{array}{l}\text { Persistent obstructive } \\
\text { lung disease }\end{array}$ \\
\hline Sex, M/F & $80 / 67$ & $33 / 25$ & $22 / 13$ & $11 / 12$ \\
\hline Age, years & $58.40 \pm 9.05$ & $64.50 \pm 9.80^{*}$ & $64.15 \pm 10.16^{*}$ & $64.96 \pm 9.50^{*}$ \\
\hline Weight, kg & $76.64 \pm 15.09$ & $80.18 \pm 16.80$ & $83.84 \pm 17.76$ & $75.36 \pm 14.37$ \\
\hline Height, m & $1.65 \pm 0.10$ & $1.66 \pm 0.10$ & $1.67 \pm 0.10$ & $1.65 \pm 0.10$ \\
\hline $\mathrm{BMI}, \mathrm{kg} / \mathrm{m}^{2}$ & $28.11 \pm 4.66$ & $28.83 \pm 5.07$ & $29.73 \pm 5.03$ & $27.64 \pm 4.98$ \\
\hline $\begin{array}{l}\text { Smoking status (Smoker/ } \\
\text { Former smoker/Nonsmoker) }\end{array}$ & $14 / 57 / 76$ & $6 / 38 / 14^{*}$ & $1 / 25 / 9^{*}$ & $5 / 13 / 5^{*}$ \\
\hline Metabolic syndrome, yes/no & $63 / 83$ & $31 / 27$ & $21 / 14$ & $10 / 13$ \\
\hline Pulmonary disease, yes/no & $7 / 140$ & $11 / 47^{*}$ & $8 / 27^{*}$ & $3 / 20^{*}$ \\
\hline Abdominal circumference, $\mathrm{cm}$ & $100.2 \pm 12.4$ & $107.4 \pm 12.8^{*}$ & $110.8 \pm 11.2^{*}$ & $105.0 \pm 14.1$ \\
\hline Hip circumference, $\mathrm{cm}$ & $105.9 \pm 10.7$ & $105.0 \pm 8.8$ & $106.6 \pm 9.0$ & $104.3 \pm 9.2$ \\
\hline Waist-to-hip ratio & $0.94 \pm 0.08$ & $1.02 \pm 0.07^{*}$ & $1.04 \pm 0.08^{*}$ & $1.0 \pm 0.07^{*}$ \\
\hline FVC, L & $3.59 \pm 0.90$ & $2.85 \pm 0.81^{*}$ & $2.72 \pm 0.73^{*}$ & $3.01 \pm 0.89^{*}$ \\
\hline FVC, \% predicted & $97.50 \pm 12.94$ & $76.8 \pm 14.74^{*}$ & $69.66 \pm 8.46^{*}$ & $85.96 \pm 16.10^{*}$ \\
\hline $\mathrm{FEV}_{1}, \mathrm{~L}$ & $2.88 \pm 0.67$ & $2.12 \pm 0.60^{*}$ & $2.20 \pm 0.56^{*}$ & $2.03 \pm 0.65^{*}$ \\
\hline $\mathrm{FEV}_{1}, \%$ predicted & $99.20 \pm 13.40$ & $73.75 \pm 14.94^{*}$ & $72.53 \pm 10.14^{*}$ & $73.32 \pm 19.58^{*}$ \\
\hline $\mathrm{FEV}_{1} / \mathrm{FVC}, \%$ & $80.70 \pm 0.05$ & $75.20 \pm 0.10^{*}$ & $81.19 \pm 0.06^{*}$ & $67.72 \pm 0.11^{*}$ \\
\hline CAC score ${ }^{b}$ & $1(0-86)$ & $36(0-379)^{*}$ & $55(0-461)^{*}$ & $3(0-166)$ \\
\hline Coronary obstruction, yes/no & $27 / 106$ & $19 / 36^{*}$ & $12 / 20^{*}$ & $7 / 16$ \\
\hline
\end{tabular}

CAC: coronary artery calcium. a Data expressed as mean \pm SD, except where otherwise indicated. ${ }^{\mathrm{b} D a t a}$ expressed as median (interquartile range). ${ }^{*} p<0.05$ vs. the normal lung function group.
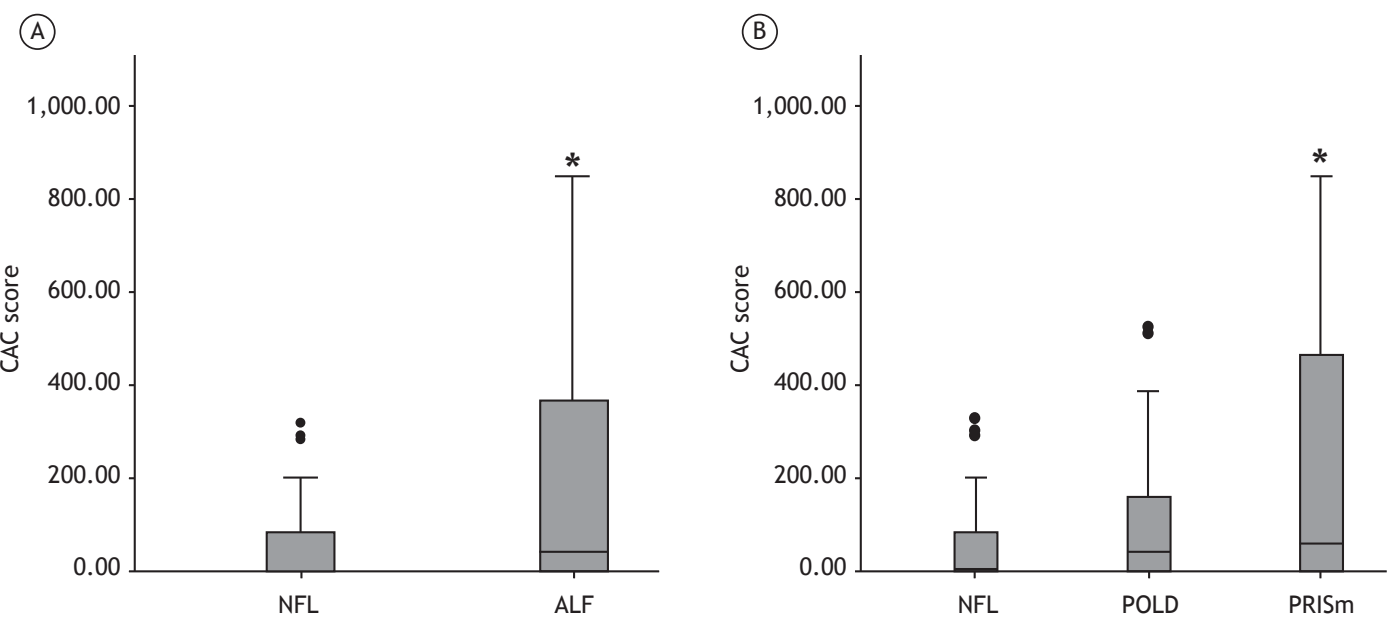

Figure 3. Median dispersion of the coronary artery calcium (CAC) score for patients with normal lung function (NLF) and abnormal lung function (ALF). In A, comparison between the NLF and ALF groups. In B, comparison between the NLF group and the persistent obstructive lung disease (POLD) and preserved ratio impaired spirometry (PRISm) subgroups. The Kruskal-Wallis test showed significant differences among the three groups. $* p<0.05$ vs. the NLF group.

former), elderly patients, and patients with CAD, having ranged from $38 \%$ to $45 \%$. This finding is consistent with those of a study evaluating CAC in smokers who were at an increased risk for lung cancer but had no previous cardiovascular disease. ${ }^{(30)}$

In elderly individuals, cardiac patients, and smokers, pulmonary function assessment is usually delayed. Symptoms are underestimated, being attributed to old age, exposure to cigarettes, or cardiovascular disease. . $^{(31)}$ The high prevalence of spirometric abnormalities in these subgroups reinforces the importance of a simple, inexpensive test to the clinical management of patients suspected of having CAD.
The prevalence and severity of obstructive coronary lesions (as assessed by the CAC score and the Duke CAD severity index) were higher in the abnormal lung function group than in the normal lung function group. These results can be attributed to the subgroup of patients with PRISm.

Of the sample as a whole, $17.2 \%$ had PRISm. Previous epidemiological studies have shown that the prevalence of PRISm is $5.1 \%$ in the general population and $12.3 \%$ in smokers. ${ }^{(32,33)}$ Mean FVC in the subgroup of PRISm patients in the present study was $<70 \%$ predicted, constituting a significant abnormality from a functional point of view. PRISm is classically associated 
with interstitial lung disease, neuromuscular disease, obesity, and metabolic syndrome. ${ }^{(34,35)}$ Reduced FVC on spirometry has been associated with increased mortality. ${ }^{(36)}$ In the present study, mean CAC scores were highest in the PRISm subgroup, indicating increased atherosclerosis.

Recent epidemiological studies have attempted to characterize and understand PRISm, and three different clusters have been identified. The first is associated with reduced TLC; the second is related to metabolic disorders; and the third is quite similar to the clinical presentation of COPD. ${ }^{(32)}$ Dyspnea, poorer performance on the six-minute walk test, emphysema, bronchial thickening, and reduced TLC have been identified as predictors of PRISm. ${ }^{(25)}$

Morbidity and dyspnea have been found to be higher in patients with PRISm than in controls with normal spirometry. Although PRISm has yet to be adequately studied, it is known to increase morbidity and worsen prognosis. Its relationship with respiratory and metabolic diseases can make it an important risk marker in the near future. ${ }^{(37,38)}$

Of the patients who were found to have abnormal lung function in the present study, $23(11.2 \%)$ had persistent obstructive lung disease. This is consistent with the reported prevalence of persistent obstructive lung disease in the general population in the city of São Paulo. ${ }^{(33)}$ In the present study, airway obstruction

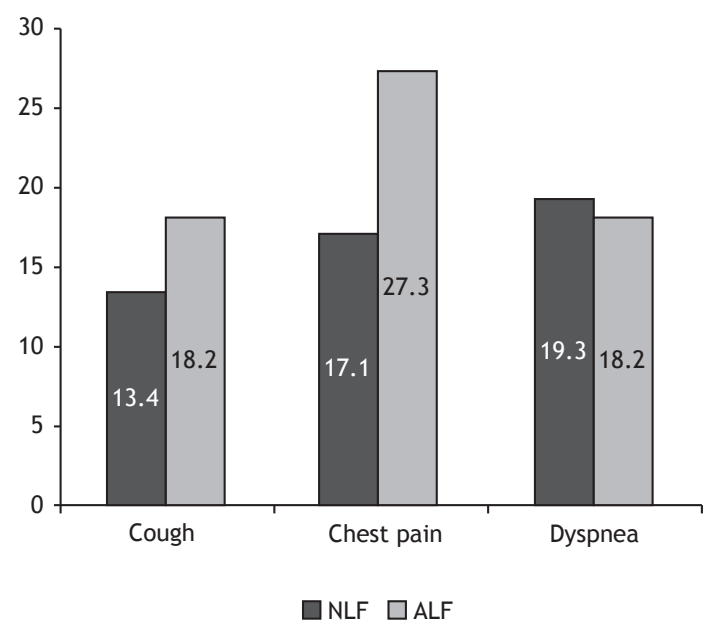

Figure 4. Proportions of patients with respiratory symptoms (cough, chest pain, and dyspnea) in the normal lung function (NLF) and abnormal lung function (ALF) groups. There were no significant differences in symptom frequency between the two groups.

Table 2. Crude odds ratios for abnormal spirometry.

\begin{tabular}{lccc}
\multicolumn{1}{c}{ Variable } & OR & 95\% Cl & p \\
Smoking & 3.21 & $1.62-6.36$ & 0.0009 \\
Age $>$ 65 years & 3.18 & $1.69-6.01$ & 0.0004 \\
Obstructive coronary lesions & 2.07 & $1.03-4.16$ & 0.04 \\
Metabolic syndrome & 1.38 & $0.74-2.57$ & 0.29 \\
Obesity & 0.79 & $0.40-1.59$ & 0.51 \\
Hypertension & 0.91 & $0.57-1.43$ & 0.75 \\
Diabetes & 0.97 & $0.53-1.77$ & 0.92 \\
\hline
\end{tabular}

was found to be most common in smokers, elderly individuals, and patients with metabolic syndrome. Such patients appear to be at increased risk and therefore constitute a population in which active case finding of and screening for COPD appear to be most effective.

In the present study, symptoms did not predict spirometric abnormalities. This finding supports the idea that pulmonary function changes precede symptoms in respiratory diseases. ${ }^{(39)}$ In addition, the fact that few of our patients had a previous diagnosis of pulmonary disease shows that pulmonary diseases are underdiagnosed in patients suspected of having cardiovascular disease. The respiratory health screening of asymptomatic patients undergoing screening for heart disease can provide valuable information.

The present study has some limitations. Because of the cross-sectional nature of the study, no causality can be established. However, the relationship between pulmonary and cardiovascular disease exists and amplifies the damaging effects of aging, smoking, and other risk factors on the respiratory and cardiovascular systems. Another limitation is that a definitive diagnosis of PRISm cannot be accurately made by spirometry alone, TLC measurement therefore being required.

In conclusion, patients screened for CAD are at an increased risk for lung function impairment, the likelihood of which is higher when the presence of CAD is confirmed. The management of patients with concomitant cardiovascular and pulmonary disease is complex. The high prevalence of lung function abnormalities in patients undergoing cardiac CT for CAD screening and the association between increased atherosclerosis (as assessed by the CAC score) and respiratory disease reinforce the importance of screening for lung disease in patients suspected of having heart disease. Spirometry is encouraged in such patients, and studies evaluating its cost-effectiveness and impact on clinical management are needed.

\section{ACKNOWLEDGMENTS}

We would like to thank Rejane Figueiredo for assisting in the statistical analysis; Karla Sabrina Gomes for assisting in patient recruitment; and the staff of the Department of Radiology of the University of São Paulo School of Medicine Hospital das Clínicas Heart Institute for their assistance. We would also like to thank Ann Conti Morcos for her assistance in the writing of this manuscript. 


\section{REFERENCES}

1. Miller MR, Crapo R, Hankinson J, Brusasco V, Burgos F, Casaburi R et al. General considerations for lung function testing. Eur Respir J 2005;26(1):153-61. https://doi.org/10.1183/09031936.05.00034505

2. Hill K, Goldstein RS, Guyatt GH, Blouin M, Tan WC, Davis LL, et al. Prevalence and underdiagnosis of chronic obstructive pulmonary disease among patients at risk in primary care. CMAJ 2010;182(7):673-8. https://doi.org/10.1503/cmaj.091784

3. Coultas DB, Mapel D, Gagnon R, Lydick E. The health impact of undiagnosed airflow obstruction in a national sample of United States adults. Am J Respir Crit Care Med. 2001;164(3):372-7. https:// doi.org/10.1164/ajrccm.164.3.2004029

4. Salge J, Izbicki M, Rodrigues Junior R, Rodrigues S. Função Pulmonar. Arakaki JSO, Nascimento O, Pereira MC, editors Hipertensão Pulmonar. 1st Ed. São Paulo: Atheneu; 2011.

5. Buffels J, Degryse J, Heyrman J, Decramer M; DIDASCO Study. Office spirometry significantly improves early detection of COPD in general practice: the DIDASCO Study. Chest. 2004;125(4):1394-9. https://doi.org/10.1378/chest.125.4.1394

6. Johns DP, Walters JA, Walters EH. Diagnosis and early detection of COPD using spirometry. J Thorac Dis. 2014;6(11):1557-69.

7. U.S. Preventive Services Task Force. Screening for chronic obstructive pulmonary disease using spirometry: U.S. Preventive Services Task Force recommendation statement. Ann Intern Med. 2008;148(7):529-34 200804010-00212

8. Zieliski J, Bednarek M; Know the Age of Your Lung Study Group. Early detection of COPD in a high-risk population using spirometric screening. Chest. 2001;119(3):731-6. https://doi.org/10.1378/ chest.119.3.731

9. Calverley PM. COPD: early detection and intervention. Chest. 2000;117(5 Suppl 2):365S-71S. https://doi.org/10.1378/chest.117.5 suppl_2.365S

10. Toljamo T, Kaukonen M, Nieminen P, Kinnula VL. Early detection of COPD combined with individualized counselling for smoking cessation: a two-year prospective study. Scand J Prim Health Care 2010;28(1):41-6. https://doi.org/10.3109/02813431003630105

11. Beaty TH, Newill CA, Cohen BH, Tockman MS, Bryant SH, Spurgeon HA. Effects of pulmonary function on mortality. J Chronic Dis 1985;38(8):703-10. https://doi.org/10.1016/0021-9681(85)90024-4

12. Speizer FE, Fay ME, Dockery DW, Ferris BG Jr. Chronic obstructive pulmonary disease mortality in six U.S. cities. Am Rev Respir Dis. 1989;140(3 Pt 2):S49-55. https://doi.org/10.1164/ajrccm/140.3_Pt_2 S49

13. Schünemann HJ, Dorn J, Grant BJ, Winkelstein W Jr, Trevisan M. Pulmonary function is a long-term predictor of mortality in the general population: 29-year follow-up of the Buffalo Health Study. Chest. 2000;118(3):656-64. https://doi.org/10.1378/chest.118.3.656

14. Sin DD, Wu L, Man SF. The relationship between reduced lung function and cardiovascular mortality: a population-based study and a systematic review of the literature. Chest. 2005;127(6):1952-9. https://doi.org/10.1378/chest.127.6.1952

15. Raggi P, Gongora MC, Gopal A, Callister TQ, Budoff M, Shaw LJ. Coronary artery calcium to predict all-cause mortality in elderly men and women. J Am Coll Cardiol. 2008;52(1):17-23. https://doi. org/10.1016/j.jacc.2008.04.004

16. Polonsky TS, McClelland RL, Jorgensen NW, Bild DE, Burke GL, Guerci $A D$, et al. Coronary artery calcium score and risk classification for coronary heart disease prediction. JAMA. 2010;303(16):1610-6. https://doi.org/10.1001/jama.2010.461

17. Anderson JL, Adams CD, Antman EM, Bridges CR, Califf RM, Casey DE Jr, et al. ACC/AHA 2007 guidelines for the management of patients with unstable angina/non-ST-Elevation myocardial infarction: a report of the American College of Cardiology/American Heart Association Task Force on Practice Guidelines (Writing Committee to Revise the 2002 Guidelines for the Management of Patients With Unstable Angina/Non-ST-Elevation Myocardial Infarction) developed in collaboration with the American College of Emergency Physicians, the Society for Cardiovascular Angiography and Interventions, and the Society of Thoracic Surgeons endorsed by the American Association of Cardiovascular and Pulmonary Rehabilitation and the Society for Academic Emergency Medicine. J Am Coll Cardiol. 2007;50(7):e1-e157. https://doi.org/10.1016/j.jacc.2007.02.013

18. Hunt SA, Abraham WT, Chin MH, Feldman AM, Francis GS, Ganiats
TG, et al. ACC/AHA 2005 Guideline Update for the Diagnosis and Management of Chronic Heart Failure in the Adult: a report of the American College of Cardiology/American Heart Association Task Force on Practice Guidelines (Writing Committee to Update the 2001 Guidelines for the Evaluation and Management of Heart Failure): developed in collaboration with the American College of Chest Physicians and the International Society for Heart and Lung Transplantation: endorsed by the Heart Rhythm Society. Circulation. 2005;112(12):e154-235. https://doi.org/10.1161/ CIRCULATIONAHA.105.167586

19. Mahler DA, Wells CK. Evaluation of clinical methods for rating dyspnea. Chest. 1988;93(3):580-6. https://doi.org/10.1378/ chest.93.3.580

20. Alberti KG, Zimmet P, Shaw J; IDF Epidemiology Task Force Consensus Group. The metabolic syndrome--a new worldwide definition. Lancet. 2005;366(9491):1059-62. https://doi.org/10.1016/ S0140-6736(05)67402-8

21. Mark DB, Nelson $C L$, Califf $R M$, Harrell FE Jr, Lee $K L$, Jones $R H$, et al. Continuing evolution of therapy for coronary artery disease. Initial results from the era of coronary angioplasty. Circulation. 1994;89(5):2015-25. https://doi.org/10.1161/01.CIR.89.5.2015

22. Miller JM, Rochitte CE, Dewey M, Arbab-Zadeh A, Niinuma $H_{\text {, }}$ Gottlieb I, et al. Diagnostic performance of coronary angiography by 64-row CT. N Engl J Med. 2008;359(22):2324-36. https://doi. org/10.1056/NEJMoa0806576

23. Miller MR, Hankinson J, Brusasco V, Burgos F, Casaburi R, Coates A et al. Standardisation of spirometry. Eur Respir J. 2005;26(2):319-38. https://doi.org/10.1183/09031936.05.00034805

24. Pereira CA, Sato T, Rodrigues SC. New reference values for forced spirometry in white adults in Brazil. J Bras Pneumol. 2007;33(4):397406. https://doi.org/10.1590/\$1806-37132007000400008

25. Wan ES, Castaldi PJ, Cho MH, Hokanson JE, Regan EA, Make $\mathrm{BJ}$, et al. Epidemiology, genetics, and subtyping of preserved ratio impaired spirometry (PRISm) in COPDGene. Respir Res. 2014;15:89. https://doi.org/10.1186/s12931-014-0089-y

26. Sociedade Brasileira de Pneumologia e Tisiologia. Diretrizes para Testes de Função Pulmonar. J Pneumol. 2002;28(Suppl 3):S1-S238.

27. Swanney MP, Ruppel G, Enright PL, Pedersen OF, Crapo RO, Miller MR, et al. Using the lower limit of normal for the FEV1/FVC ratio reduces the misclassification of airway obstruction. Thorax 2008;63(12):1046-51. https://doi.org/10.1136/thx.2008.098483

28. Colla $\mathrm{CH}$, Sequist TD, Rosenthal MB, Schpero WL, Gottlieb DJ Morden NE. Use of non-indicated cardiac testing in low-risk patients: Choosing Wisely. BMJ Qual Saf. 2015;24(2):149-53. https://doi. org/10.1136/bmjqs-2014-003087

29. Roberts NJ, Smith SF, Partridge MR. Why is spirometry underused in the diagnosis of the breathless patient: a qualitative study. BMC Pulm Med. 2011;11:37. https://doi.org/10.1186/1471-2466-11-37

30. Shemesh J, Henschke Cl, Farooqi A, Yip R, Yankelevitz DF, Shaham $D$, et al. Frequency of coronary artery calcification on low-dose computed tomography screening for lung cancer. Clin Imaging. 2006;30(3):181-5. https://doi.org/10.1016/j.clinimag.2005.11.002

31. Langsetmo L, Platt RW, Ernst $P$, Bourbeau J. Underreporting exacerbation of chronic obstructive pulmonary disease in a longitudinal cohort. Am J Respir Crit Care Med. 2008;177(4):396401. https://doi.org/10.1164/rccm.200708-12900C

32. Wan ES, Hokanson JE, Murphy JR, Regan EA, Make BJ, Lynch $D A$, et al. Clinical and radiographic predictors of GOLD-unclassified smokers in the COPDGene study. Am J Respir Crit Care Med. 2011;184(1):57-63. https://doi.org/10.1164/rccm.201101-00210C

33. Nonato NL, Nascimento OA, Padilla RP, de Oca MM, Tálamo C, Valdivia G, et al. Occurrence of respiratory symptoms in persons with restrictive ventilatory impairment compared with persons with chronic obstructive pulmonary disease: The PLATINO study. Chron Respir Dis. 2015;12(3):264-73. https://doi. org/10.1177/1479972315588004

34. Fimognari FL, Pasqualetti P, Moro L, Franco A, Piccirillo G, Pastorelli $\mathrm{R}$, et al. The association between metabolic syndrome and restrictive ventilatory dysfunction in older persons. J Gerontol A Biol Sci Med Sci. 2007;62(7):760-5. https://doi.org/10.1093/gerona/62.7.760

35. Santana AN, Souza R, Martins AP, Macedo F, Rascovski A, Salge JM. The effect of massive weight loss on pulmonary function of morbid obese patients. Respir Med. 2006;100(6):1100-4. https://doi. org/10.1016/j.rmed.2005.09.021

36. Guerra S, Sherrill DL, Venker C, Ceccato CM, Halonen M, Martinez 
AgP

FD. Morbidity and mortality associated with the restrictive spirometric pattern: a longitudinal study. Thorax. 2010;65(6):499-504. https://doi. org/10.1136/thx.2009.126052

37. Mannino DM, Holguin F, Pavlin BI, Ferdinands JM. Risk factors for prevalence of and mortality related to restriction on spirometry: findings from the First National Health and Nutrition Examination Survey and follow-up. Int J Tuberc Lung Dis. 2005;9(6):613-21.

38. Mannino DM, Ford ES, Redd SC. Obstructive and restrictive lung disease and functional limitation: data from the Third National Health and Nutrition Examination. J Intern Med. 2003;254(6):540-7. https:// doi.org/10.1111/j.1365-2796.2003.01211.x

39. Scanlon PD, Connett JE, Waller LA, Altose MD, Bailey WC, Buist $A S$, et al. Smoking cessation and lung function in mild-to-moderate chronic obstructive pulmonary disease. The Lung Health Study. Am J Respir Crit Care Med. 2000;161(2 Pt 1):381-90. https://doi. org/10.1164/ajrccm.161.2.9901044 